\title{
Separation of Lignocellulosic Biomass Components by Alkali Pretreatment
}

\author{
Parmeshwar Patil*, Prathamesh Wadekar, Mallikarjun Patil and \\ Arvind Lali \\ DBT-ICT Centre for Energy Biosciences, Institute of Chemical Technology \\ (Formerly UDCT), Mumbai, India \\ *Corresponding Author: Parmeshwar Patil, DBT-ICT Centre for Energy \\ Biosciences, Institute of Chemical Technology (Formerly UDCT), Mumbai, India.
}

\author{
Received: February 13, 2020 \\ Published: March 12, 2020 \\ (C) All rights are reserved by Parmeshwar \\ Patil., et al.
}

\begin{abstract}
Traditional pretreatment methods have several disadvantages, including lower efficiency in terms of cellulose purity, high cost and incomplete separation of biomass components. Considering this, we compared different pretreatment processes and studied their effect on separation of biomass components. Effective delignification was achieved by alkali pretreatment with sodium hydroxide and ammonia. Among alkalis, sodium hydroxide treatment requires less severe process condition like lower concentration, temperature and pressure compared to ammonia pretreatment and produces enzyme amenable substrate, which made sodium hydroxide ideal for biomass pretreatment. Efforts were mounted to optimize sodium hydroxide pretreatment on wheat straw in terms of reaction temperature, reaction time and reagent concentration to produce enzymatically amenable substrate. The best experimental results were obtained when biomass was treated with $2 \%$ sodium hydroxide at $130^{\circ} \mathrm{C}$ for 30 minutes, which was found to extract lignin and significant amount of hemicellulose from biomass.
\end{abstract}

Keywords: Biomass; Alkali Pretreatment; Precipitation; Separation

\section{Introduction}

Elevated worldwide demand of energy for the production of transportation fuels, chemicals and apprehension over global climate change have led to rising interest in the development of alternative energy and chemicals that can displace fossil transportation fuel [1]. Production of biofuels from renewable biomass resources offer a strategic advantage to encourage sustainable development and to complement conventional energy sources in meeting the speedily increasing requirements for transportation fuels linked with high economic growth, as well as in meeting the energy needs of India's gigantic population. Lignocellulosic materials are one of the most promising feedstock as natural and renewable resource that can be used in the production of biofuels [2]. Generally, the process of converting lignocellulosic biomass to bioethanol consists of three major steps: pretreatment of biomass to break down the main components, hydrolysis of the broken components into sugars, fermentation of sugars to ethanol [3].

Lignocellulosic biomass is mainly composed of cellulose, hemicellulose and lignin. Cellulose and hemicellulose hydrolysed to produce hexose (mainly glucose) and pentose (mainly xylose). Cellulose, hemicelluloses and lignin forms the backbone of lignocellulose, initially lignin is connected with cellulose and hemicellulose by hydrogen bonds and ether and ester bonds [4]. Cellulose in biomass present in crystalline form which is intractable to be hydrolyzed to its monomeric units by hydrolytic enzyme [5]. Dif- ferent pretreatment process required to make cellulose and hemicellulose accessible for enzyme hydrolysis. Pretreatment process separate these carbohydrate polymers from lignin, and convert crystalline cellulose to amorphous cellulose, making it appropriate for enzymatic hydrolysis.

The strategies to select a pretreatment technology for a particular biomass depend on the biomass composition and target products. It is highly desirable to development a cost effective pretreatment technology featuring efficiency recovery of all biomass components, and negligible production of inhibitory by-products [6]. Various pretreatment technologies have been extensively studied to process a range of biomass for cellulosic ethanol production, but each pretreatment has its intrinsic advantages and disadvantages. An effective pretreatment is characterized by several criteria: preserving cellulose and hemicellulose fractions, limiting formation of inhibitors due to degradation products, minimizing energy input, and being cost effective. Except for these criteria, several other factors are also needed to be considered, including recovery of high value-added co-products (e.g., lignin), pretreatment catalyst, catalyst recycling, and waste treatment [7]. When comparing various pretreatment options, all the above mentioned criteria should be comprehensively considered as a basis chemical pretreatment is found to be best. Chemical pretreatment that have been studied to date have had the primary goal of improving the biodegradability of cellulose by removing lignin and/or hemi- 
cellulose, and to a lesser degree decreasing the degree of polymerization (DP) and crystallinity of the cellulose component [8]. To achieve the desired separation of biomass components with efficient recoveries of all the components most of the researches developed multistage chemical pre-treatment process. Different technologies and severities should be applied for multiple purpose optimizations a composite pretreatment streamline with separate stages was suggested [9].

Researchers applied different temperatures in two-stage dilute-acid and alkali pretreatment of different biomass. A low temperature $\left(140^{\circ} \mathrm{C}\right)$ followed by a higher temperature $\left(170^{\circ} \mathrm{C}\right)$ was employed and achieving a $92 \%$ xylose recovery with only $2 \%$ of xylose degraded to furfural. However, the whole process focused only on maximizing xylose yield, leaving glucan, accounting for $42 \%$ of the raw material, in a low conversion rate [10]. Nguyen., et al. were the first to conduct a two-stage dilute acid pretreatment with separate severities, aiming to recover hemicellulose and cellulose in different stages [11]. The first stage was at low severity to maximize xylose recovery and second stage under severer conditions to hydrolyze the remaining cellulose which result in the degradation of cellulose ultimately the desired sugar recoveries were not achieved [12]. The major disadvantage of multistage pretreatment is the higher cost of process to produce the low value product like ethanol. Therefore it become obligatory to shift from multistage pretreatment to single stage pretreatment to reduce the cost of process with efficient recoveries of all the biomass components.

\section{Materials and Methods \\ Materials \\ Raw materials}

As India is the largest producer of wheat and wheat straw which is the representative of all grassy biomasses was used for the pretreatment studies. Wheat straw was obtained from the fields in northern India (Uttarakhand). Straw was milled to 600 micron size from $5 \mathrm{~cm}$ by size reduction unit supplied by Premium Pullman (Ahmedabad, India). Such size-reduced biomass was used for further pretreatment reactions.

\section{Chemicals and reagents}

Sulphuric acid, Xylose, Arabinose and Ethanol were procured from S. D. Fine Chemicals (Mumbai, India). Sodium hydroxide was from Merck Specialities India Limited and calcium carbonate and Glucose were procured from Himedia, India. Furfural and Hydroymethyl furfural (HMF) were purchased from SRL, India and Sigma-Aldrich (St. Louis, USA) respectively. Polyelectrolytes were procured from Rishabh Metals and Chemicals Pvt. Ltd., Mumbai.
Analytical methods

Determination of moisture content

Moisture content was determined using an Infrared moisture analyzer (Preciza 64XM 120, Preciza, Switzerland) in accordance to the NREL LAP (8). About 1 gm of size reduced wheat straw sample was evenly spread over the aluminium pan kept in the moisture analyzer at $30^{\circ} \mathrm{C}$. Analysis temperature of $105^{\circ} \mathrm{C}$ was achieved via slow ramping mode and a weight change of less than $0.05 \%$ over a time of 60 seconds was taken as the endpoint. The \% loss in weight was noted as the moisture content of wheat straw [13].

\section{Determination of ash content}

Quartz crucibles were kept overnight at $575^{\circ} \mathrm{C}$ in a muffle furnace and were weighed to constant weight. Known amount of biomass samples (0.5-1.0gm) were weighed in pre-weighed crucibles and heated to $105^{\circ} \mathrm{C}$ to remove moisture. The crucibles were then heated to $575^{\circ} \mathrm{C}$ for $4 \mathrm{hrs}$ to constant weight. The weight of ash remaining was calculated as percentage of the original dry weight of sample [14].

\section{Determination of structural carbohydrates}

In $100 \mathrm{ml}$ conical flask, 72\% (w/w) sulphuric acid (3 mL) was added to $0.3 \mathrm{~g}$ of biomass sample. The flask was maintained at $30^{\circ} \mathrm{C}$ for 60 min with stirring. The acid was then diluted to $4 \%$ by addition of water and samples were autoclaved at $121^{\circ} \mathrm{C}$ for $60 \mathrm{~min}$. The contents were filtered through a porcelain crucible to separate solids for lignin analysis and the liquid fraction was analyzed using high performance liquid chromatography (HPLC). The analyses were performed on Agilent $1200 \mathrm{HPLC}$ using Aminex $87 \mathrm{H}$ column maintained at $50^{\circ} \mathrm{C}$ with refractive index detector (RID). $5 \mathrm{mM}$ $\mathrm{H}_{2} \mathrm{SO}_{4}$ was used as the mobile phase with flow rate of $0.6 \mathrm{ml} / \mathrm{min}$. Samples were filtered $(0.45 \mu \mathrm{m})$ prior to the analysis of glucose, xylose and arabinose [15].

\section{Determination of Acid insoluble lignin}

Filtered solids obtained after acid hydrolysis of samples were analyzed in the pre-weighed crucibles for lignin content. After filtration, the samples were kept in the oven and heated overnight to $105^{\circ} \mathrm{C}$. The crucibles containing these samples were weighed to constant weight and then placed in the muffle furnace and heated to $575^{\circ} \mathrm{C}$ for $4 \mathrm{hrs}$ to constant weight. Lignin content was calculated from the procedure specified in NREL Lab protocol for lignin and structural carbohydrates.

\section{Determination of alkali soluble lignin}

Lignin in lignin-ammonia extract was estimated by spectrophotometry. Lignin solution was appropriately diluted and absorbance was measured at $280 \mathrm{~nm}$. Concentration of lignin was measured using following equation, 
Concentration of lignin $=\frac{(0 . D \cdot a t 280 \mathrm{~nm} * \text { Dilution factor })}{24.7 * \text { path length }}$

Where, O.D. - optical density

Molar extinction coefficient -24.7 .

Experimental methods

Preprocessing of biomass

Wheat straw was cut manually into pieces of about $2-5 \mathrm{~cm}$ in length and further size reduction was carried out to an average size of 600 micron by a size reduction unit by Premium Pullman, Ahmedabad, India.

\section{Screening of different pretreatment methods}

Experiments in terms of concentration of nitric acid, sodium hydroxide and ammonia were performed to select best method for the fractionation of biomass. Size reduced straws (average $5 \mathrm{~mm}$ length and $<1 \mathrm{~mm}$ thick; $7 \mathrm{~g}$ ) was mixed with $100 \mathrm{ml}$ of nitric acid/ sodium hydroxide/ammonia in water in desired concentration, at $30^{\circ} \mathrm{C}$. The resultant slurry was transferred into a $300 \mathrm{ml}$ high-pressure reactor (Amar Equipments Pvt Ltd Mumbai) equipped with an agitator. The reactor was then heated to the desired temperature and the temperature was maintained for 15 minutes. The reaction mixture was then allowed to cool and later subjected to either vacuum filtration through a nylon bolting cloth (BSS 400, $38 \mu$ ). The residue was washed with water for removal of adsorbed alkali. The washings and filtrate were pooled and the resultant solution was named as reaction extract. The residue was subjected to analysis of carbohydrates and lignin content. The nitric acid, sodium hydroxide and ammonia concentrations were varied from $0.5 \%$ to $2.5 \% \mathrm{w} / \mathrm{w}$. The temperature conditions employed were $110^{\circ} \mathrm{C}$.

\section{Fractionation of wheat straw by sodium hydroxide}

Optimization experiments in terms of concentration of sodium hydroxide and temperature were performed for effective fractionation of biomass. Size reduced straws (average $5 \mathrm{~mm}$ length and $<1 \mathrm{~mm}$ thick; $7 \mathrm{~g}$ ) was mixed with $100 \mathrm{ml}$ of sodium hydroxide $(\mathrm{NaOH})$ in water in desired concentration, at $30^{\circ} \mathrm{C}$. The resultant slurry was transferred into a $300 \mathrm{ml}$ high-pressure reactor (Amar Equipments Pvt Ltd Mumbai) equipped with an agitator. The reactor was then heated to the desired temperature and the temperature was maintained for 15 - 30 minutes. The reaction mixture was then allowed to cool and later subjected to either vacuum filtration through a nylon bolting cloth (BSS 400, $38 \mu$ ). The residue was washed with water for removal of adsorbed alkali. The washings and filtrate were pooled and the resultant solution was named as alkaline extract. The residue was subjected to analysis of carbohydrates and lignin content. Similar sets of experiments were carried out using varying concentrations of sodium hydroxide at different temperatures. The sodium hydroxide concentrations were varied from $0.5 \%$ to $2.5 \% \mathrm{w} / \mathrm{w}$. The temperature conditions employed were $110^{\circ} \mathrm{C}, 130^{\circ} \mathrm{C}$ and $150^{\circ} \mathrm{C}$.

\section{Process scale up in 5L batch reactor}

To investigate the efficacy and reproducibility of sodium hydroxide treatment at a higher scale, a high-pressure batch reactor of 5L (Snowtech Equipments, Navi Mumbai, India) capable of handling 60 bar pressure and $200^{\circ} \mathrm{C}$ temperature was employed. The typical reaction conditions were $400 \mathrm{~g}$ of wheat straw in $4 \mathrm{~L}$ of sodium hydroxide solution $(2 \% \mathrm{w} / \mathrm{w})$ reacted for 30 minutes at $130^{\circ} \mathrm{C}$. The reacted slurry was then filtered using a nylon cloth

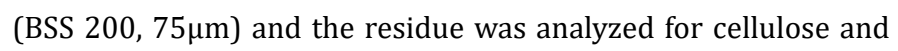
lignin content.

\section{Results and Discussion}

Compositional analysis of wheat straw

Wheat straw is an attractive substrate for second generation ethanol production because it will complement and augment wheat production rather than competing with food production. Table 1 shows the compositional analysis of wheat straw carried out using ASTM protocols described earlier. Being grassy, wheat straw has lower percentage of lignin and higher percentage of cellulose and hemicelluloses compare to non-grassy biomass.

\begin{tabular}{|l|c|}
\hline \multicolumn{1}{|c|}{ Biomass components } & $\mathbf{\%}(\mathbf{w} / \mathbf{w})$ \\
\hline Moisture & 10.11 \\
\hline Cellulose & 40.19 \\
\hline Xylose & 21.87 \\
\hline Arabinose & 4.05 \\
\hline Lignin & 20.09 \\
\hline Ash & 5.22 \\
\hline
\end{tabular}

Table 1: Compositional analysis of wheat straw.

\section{Screening of different chemical pretreatment methods}

The purpose of pretreatment is to make lignocellulosic biomass amenable to enzymatic reactions (saccharification) with reasonable processing cost. Major outcomes of pretreatment include decrease of lignin content, increase of surface area, and decrease of crystallinity of the biomass; all of which result in enhanced enzymatic hydrolysis rate and yield. Considering these objectives, different chemical pretreatment methods were screened to produce enzyme amenable substrate. Most commonly used pretreatment method like nitric acid; sodium hydroxide and ammonia pretreatment were screened. Sulfuric acid was not used for the pretreatment because dilute acid treatment causes corrosion to reactor system and mandates expensive construction material. Therefore sulfuric acid was not good choice for the development of cost effective pretreatment process. 


\section{Nitric acid pretreatment}

Effects were mounted to screen chemical pretreatment methods, wheat straw which is representative of grassy biomass treated with different chemical regents. Wheat straw treated with nitric acid in the concentration range of 0.5 to $2 \%(\mathrm{w} / \mathrm{w})$ at $110^{\circ} \mathrm{C}$. It was found that glucose recovery is higher with lower concentration of nitric acid but at the same concentration delignification was poor (Figure 1). Wheat straw pretreatment with higher concentration of nitric acid results in efficient hemicellulose release in the form of xylose but causes decline in the glucose recovery. The major drawback in the nitric acid treatment was the partial delignification of biomass due to which enzymes not able to hydrolyze the pretreated biomass. Biomass pretreatment with higher concentration of nitric acid results in the formation of inhibitory product like furfural and hydroxymethylfurfural (HMF) which inhibit the fermentation process.

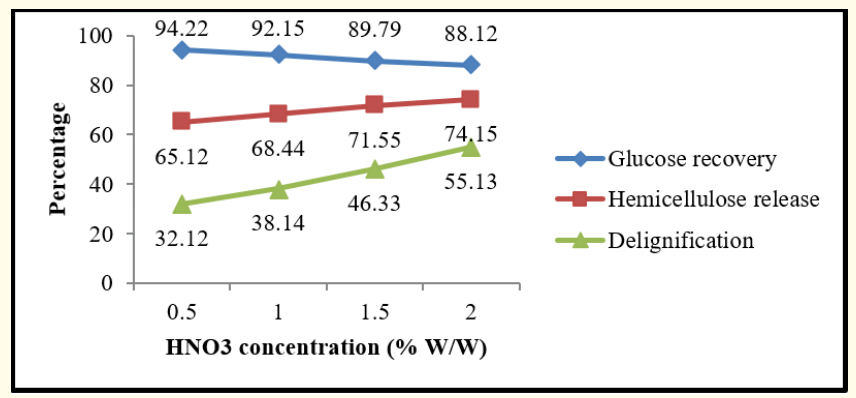

Figure 1: Pretreatment of wheat straw with $\mathrm{HNO}_{3}$ at $110^{\circ} \mathrm{C}$ for 15 minutes.

\section{Sodium hydroxide pretreatment}

Wheat straw treated with sodium hydroxide in the concentration range of 0.5 to $2.5 \%(\mathrm{w} / \mathrm{w})$ at $110^{\circ} \mathrm{C}$ for 15 minutes. It was found that glucose recovery is higher with lower concentration of sodium hydroxide (Figure 2). Efficient delignification has been achieved with the sodium hydroxide pretreatment which results in the production of enzyme amenable substrate. The use of an alkali causes the degradation of ester resulting in structural alteration of lignin and partial solubilization of hemicellulose.

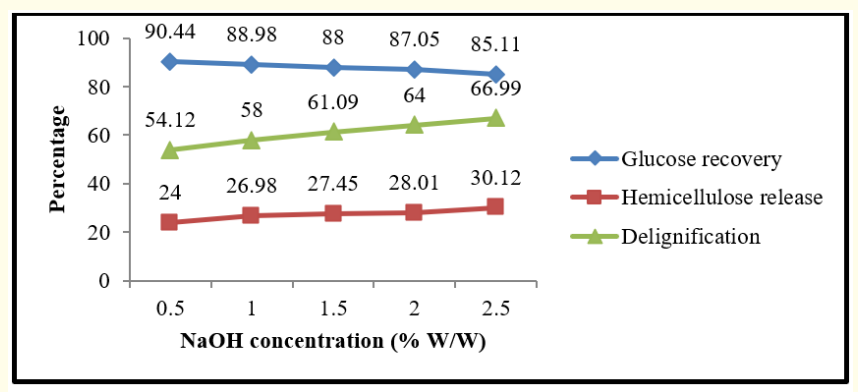

Figure 2: Pretreatment of wheat straw with $\mathrm{NaOH}$ at $110^{\circ} \mathrm{C}$ for 15 minutes.

\section{Ammonia pretreatment}

Ammonia pretreatment behaves similar to sodium hydroxide treatment. Efficient delignification has been achieved but it requires higher concentration of ammonia (10 - 25\% w/w). Substrate produced after the ammonia treatment was enzymatically amenable. Hemicelluloses realized partially and in polymeric form (Figure 3).

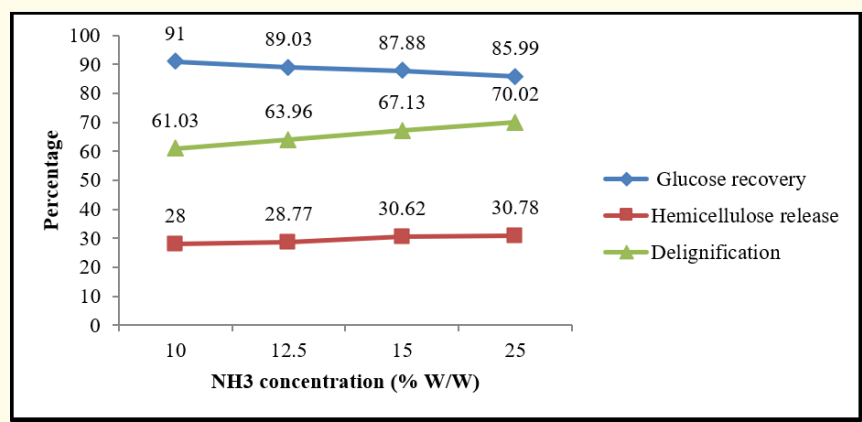

Figure 3: Pretreatment of wheat straw with $\mathrm{NH}_{3}$ at $110^{\circ} \mathrm{C}$ for 15 minutes.

\section{Comparison of chemical pretreatment methods}

Comparison of all the three methods showed major delignification and enzymatically amenable substrate has been produced by alkali i.e. sodium hydroxide and ammonia treatment. Among alkali treatment, optimum delignification achieved with lower concentration of sodium hydroxide in comparison of ammonia concentration. Pungent smell of ammonia is also point of concern from the view of scale up which indicates sodium hydroxide is the best candidate for the pretreatment of biomass. However, optimization was required to develop a cost effective process for maximum sugar recovery, delignification and enzyme hydrolysis. Comparison of three chemical pretreatment showed in table 2.

\begin{tabular}{|l|c|c|c|}
\hline & $\mathbf{H N O}_{\mathbf{3}}$ & $\mathbf{N a O H}$ & $\mathbf{N H}_{\mathbf{3}}$ \\
\hline Glucose recovery & Efficient & Efficient & Efficient \\
\hline Hemicellulose release & Efficient & Partial & Partial \\
\hline Enzignification & Partial & Efficient & Efficient \\
\hline $\begin{array}{l}\text { Inhibitory product } \\
\text { formation }\end{array}$ & Yoor & Good & Good \\
\hline Operating condition & $\begin{array}{c}\text { Higher } \\
\text { pressure } \\
\text { and con- } \\
\text { centration }\end{array}$ & $\begin{array}{c}\text { Lower } \\
\text { pressure } \\
\text { and con- } \\
\text { centration }\end{array}$ & $\begin{array}{c}\text { Higher } \\
\text { pressure } \\
\text { and con- } \\
\text { centration }\end{array}$ \\
\hline Odour & No & No & Yes \\
\hline
\end{tabular}

Table 2: Comparison of different pretreatment methods. 
Development of single step sodium hydroxide pretreatment process for bioethanol production

Pretreatment can effectively overcome both chemical and physical barriers and enhance the enzymatic digestibility of biomass if proper chemical reagents/catalysts are applied. For selection of optimal treatment reagent/catalyst, a strategy must be set for the removal of lignin and/or hemicellulose. Pretreatment at high temperature with short reaction time could improve the enzymatic digestibility of the treated solid significantly. Ideal pretreatment process should have lower energy cost, maximum recovery of biomass components, lower capital cost, high cellulose accessibility to enzymes and lower chemical consumption. With reference to these objectives efforts were mounted to develop the cost effective pretreatment process using sodium hydroxide. Different concentrations of sodium hydroxide were screened in the range of 0.5 to $2 \%(\mathrm{w} / \mathrm{w})$ at different temperature with variable time interval. It was observed that pretreatment with lowest $(0.5 \%)$ concentrations of sodium hydroxide result in maximum glucose recovery at all the temperatures tested. However, the delignification profiles showed presence of lignin in the residue indicating partial removal of lignin. Cellulose degradation was observed at higher temperatures $\left(150^{\circ} \mathrm{C}\right)$, which was evident from charring of the residue and significant loss in weight. At sodium hydroxide concentration of $2.5 \%$, lignin removal improved marginally at $130^{\circ} \mathrm{C}$ but was accompanied by loss of cellulose. Hemicellulose release remained satisfactory similar to earlier $(0.5 \%-2 \% \mathrm{NaOH})$ reaction conditions. The best results were obtained at concentration of $2 \%(\mathrm{w} / \mathrm{v})$ sodium hydroxide at $130^{\circ} \mathrm{C}$ for 30 minutes which resulted in delignification and cellulose recovery of over $85 \%$ along with partial removal of hemicellulose (Figure 4. a-e). Rate of heating for all the experiments were $12^{\circ} \mathrm{C} / \mathrm{Min}$.



(a)

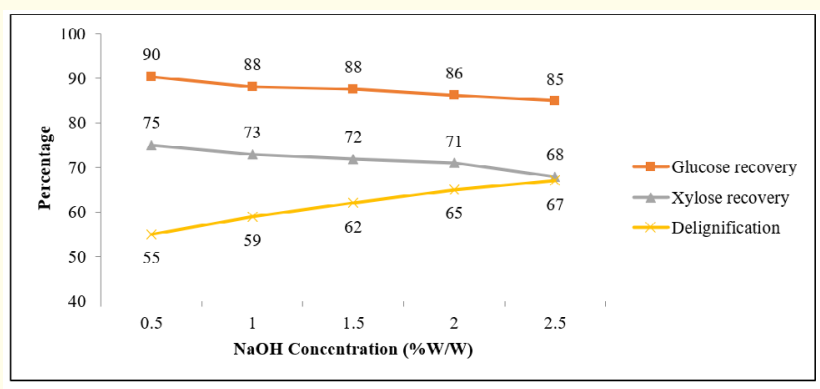

(b)

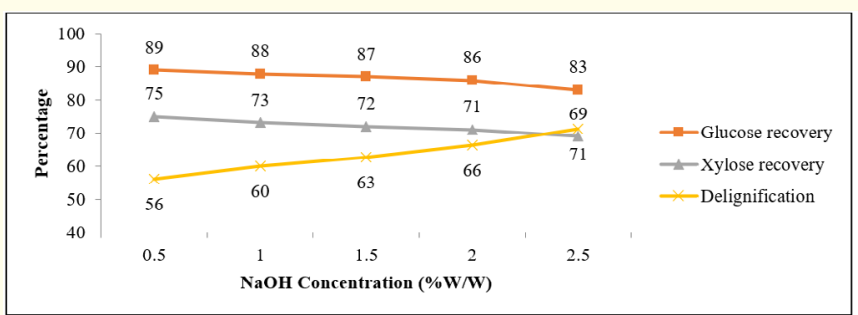

(c)

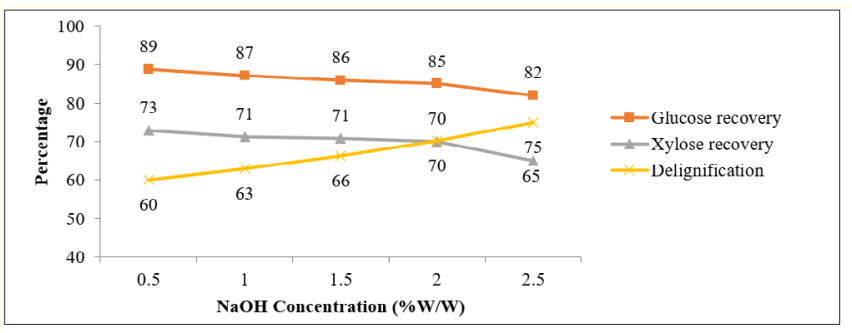

(d)

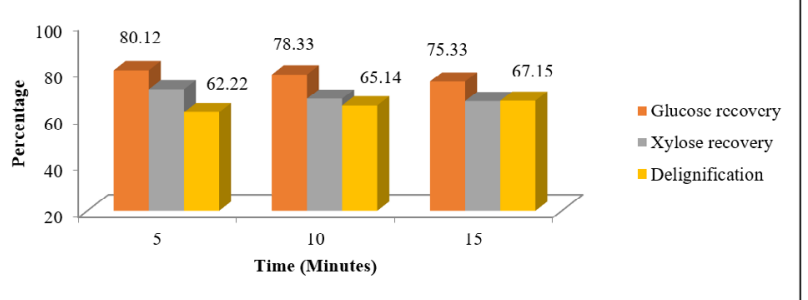

(e)

Figure 4: Effect of various concentrations of $\mathrm{NaOH}$ on wheat straw at different temperatures, (a) Effect of $\mathrm{NaOH}$ on wheat straw at $110^{\circ} \mathrm{C}$ for 15 minutes, (b) Effect of $\mathrm{NaOH}$ on wheat straw at $110^{\circ} \mathrm{C}$ for 30 minutes, (c) Effect of $\mathrm{NaOH}$ on wheat straw at $130^{\circ} \mathrm{C}$ for 15 minutes, (d) Effect of $\mathrm{NaOH}$ on wheat straw at $130^{\circ} \mathrm{C}$ for 15 minutes (e) Effect of $0.5 \%$ (w/w) $\mathrm{NaOH}$ at $150^{\circ} \mathrm{C}$ on wheat straw at different time interval.

At higher temperature $\left(150^{\circ} \mathrm{C}\right)$ exhibited cellulose degradation. With lower concentration of sodium hydroxide the extent of degradation was reduced. This indicates that lower concentration of alkali confers some degree of protection to cellulose against degradation, a phenomenon which can be explained on the basis of stabilization reaction in which the terminal glucose residue of the cellulose gets converted into a substituted glucometasaccharinic acid which stops further breaking of cellulose chain. The general trend of cellulose degradation at higher temperatures can be explained on the basis of random alkali scission of glycosidic bonds present in cellulose at temperatures higher than $150^{\circ} \mathrm{C}$ as reported by Knill and Kennedy. Delignification refers to removal of lignin from the biomass into the liquid fraction of alkali, leaving a residue comprising mainly of cellulose. Delignification can be attributed to the action of sodium hydroxide, which dissolves the lignin from the (lignin rich) middle lamellae and secondary cell wall thus separating it from the cellulose fibres. Therefore, sodium hydroxide pretreat- 
ment result in major delignification with minimum degradation of cellulose, and produced cellulose is enzymatically amenable.

\section{Process scale up in $5 \mathrm{~L}$ batch reactor}

Wheat straw fractionation under optimal conditions of sodium hydroxide and temperature was reproduced in a $5 \mathrm{~L}$ high-pressure batch reactor. $400 \mathrm{~g}$ of wheat straw were reacted with $4 \mathrm{~L}$ of $2 \%$ sodium hydroxide solution for $30 \mathrm{~min}$. at $130^{\circ} \mathrm{C}$. Delignification of $70 \%$ with more than $85 \%$ glucose recovery was achieved consistently in several runs. The scaled up reactions were used as a regular source of cellulose and hemicellulose-lignin mixture for further work in this study.

\section{Conclusions}

A range of pretreatment methods have been screened to improve enzymatic saccharification of lignocellulosic biomass. Alkaline $(\mathrm{NaOH})$ pretreatment has found to be the one of the most efficient method because of effective delignification, minimal interaction with hemicellulose, and mild reaction conditions. In addition, alkali pretreatment is highly selective for separation of lignin.

\section{Bibliography}

1. Z Anwar., et al. "Agro-industrial lignocellulosic biomass a key to unlock the future bio-energy: A brief review". Journal of Radiation Research and Applied Science 7 (2014): 163-173.

2. Y Zheng., et al. "Overview of biomass pretreatment for cellulosic ethanol production". International Journal of Agricultural and Biological Engineering 2.3 (2009): 51-68.

3. M Foston J., et al. "Biomass characterization: recent process in understanding biomass recalcitrance". Ingram Micro 8 (2012): 4-22.

4. JS Kim., et al. "A review on alkaline pretreatment technology for bioconversion of lignocellulosic biomass". Bioresource Technology (2015).

5. H Wulfhorst., et al. "Tippkeotter, Compositional analysis of pretreated (beech) wood using differential scanning calorimetry and multivariate data analysis". Tetrahedron (2016): 1-6.

6. SR Decker., et al. "High-throughput screening of recalcitrance variations in lignocellulosic biomass: total lignin, lignin monomers, and enzymatic sugar release". Journal of Visualized Experiments 103 (2015): e53163.

7. J Lindedam., et al. "Evaluation of high throughput screening methods in picking up differences between cultivars of lignocellulosic biomass for ethanol production". Biomass and Bioenergy 66 (2014): 261-267.
8. ASluiter B Hames., et al. "Determination of structural carbohydrates and lignin in biomass laboratory analytical procedure". Golden, CO: National Renewable Energy Laboratory (2008).

9. FC Moreira-Vilar, et al. The acetyl bromide method is faster, simpler and presents best recovery of lignin in different herbaceous tissues than klason and thioglycolic acid methods (2014).

10. Ragauskas AJ., et al. "The path forward for biofuels and biomaterials". Science 311.5760 (2006): 484-489.

11. Yan L., et al. "Hot water pretreatment of lignocellulosic biomass: an efective and environmentally friendly approach to enhance biofuel production". Chemical Engineering and Technology 39.10 (2016): 1759-1770.

12. Pu Y., et al. "Assessing the molecular structure basis for biomass recalcitrance during dilute acid and hydrothermal pretreatments". Biotechnol Biofuels 6.1 (2013): 1.

13. Meng X., et al. "An in-depth understanding of biomass recalcitrance using natural poplar variants as the feedstock". Chem Sus Chem 10.1 (2016): 139-150.

14. Chang VS and Holtzapple MT. "Fundamental factors affecting biomass enzymatic reactivity". Applied Biochemistry and Biotechnology 84 (2000): 5-37.

15. A Sluiter., et al. "Determination of structural carbohydrates and lignin in biomass laboratory analytical procedure". Golden, CO: National Renewable Energy Laboratory (2008).

\section{Assets from publication with us}

- Prompt Acknowledgement after receiving the article

- Thorough Double blinded peer review

- Rapid Publication

- Issue of Publication Certificate

- High visibility of your Published work

Website: https://www.actascientific.com/

Submit Article: https://www.actascientific.com/submission.php Email us: editor@actascientific.com

Contact us: +919182824667 